\title{
Occurrence and dry deposition of organophosphate esters in atmospheric particles over the northern South China Sea
}

\author{
Senchao Lai ${ }^{a}$, Zhiyong Xie ${ }^{\mathrm{b}, *}$, Tianli Song ${ }^{a}$, Jianhui Tang ${ }^{\mathrm{c}}$, Yingyi Zhang ${ }^{\mathrm{a}, *}$, Wenying Mi ${ }^{\mathrm{b}}$, Jinhu Peng ${ }^{\mathrm{d}}$, \\ Yan Zhao ${ }^{a}$, Shichun Zou ${ }^{d}$, Ralf Ebinghaus ${ }^{b}$ \\ ${ }^{a}$ Guangdong Provincial Key Laboratory of Atmospheric Environment and Pollution Control, College of Environment and Energy, South China University of Technology, \\ Guangzhou, China \\ ${ }^{\mathrm{b}}$ Helmholtz-Zentrum Geesthacht, Centre for Materials and Coastal Research, Institute of Coastal Research, Geesthacht, Germany \\ ${ }^{\mathrm{c}}$ Key Laboratory of Coastal Zone Environmental Processes, Yantai Institute of Coastal Zone Research, CAS, Yantai, China \\ ${ }^{\mathrm{d}}$ School of Marine Sciences, Sun Yat-Sen University, Guangzhou, China
}

\section{H I G H L I G H T S}

- TCEP was the predominant OPE compound found in the marine aerosol particles.

- Air mass transport plays an important role for varying OPE concentrations.

- The dry deposition input of the total OPEs is estimated.

\section{A R T I C L E I N F O}

\section{Article history:}

Received 11 December 2014 Received in revised form 6 February 2015

Accepted 9 February 2015

Available online 27 February 2015

Handling Editor: J. de Boer

\section{Keywords:}

Organophosphate esters

Northern South China Sea

Particulate matter

Air transport

Dry deposition

\section{G R A P H I C A L A B S T R A C T}

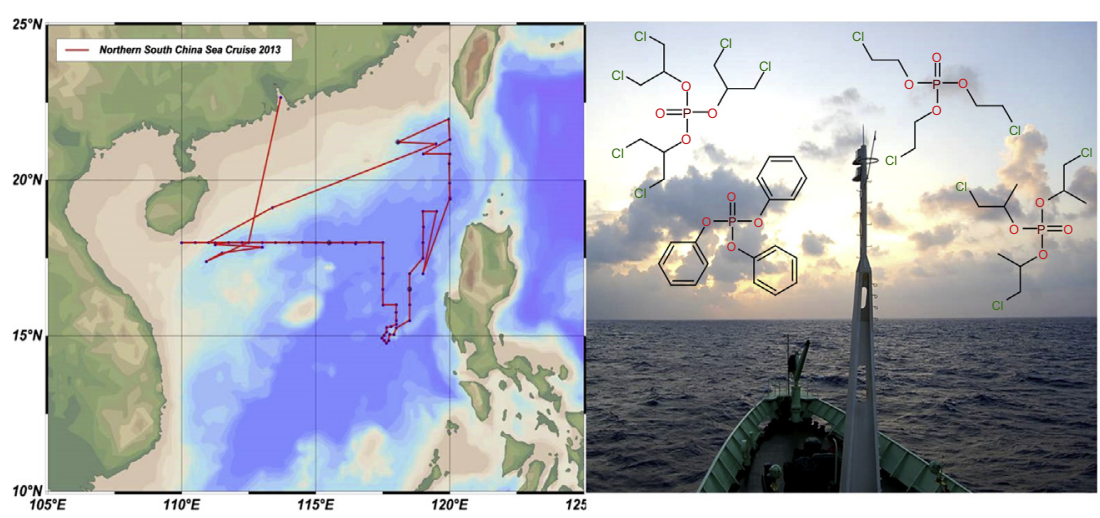

A B S T R A C T

Nine organophosphate esters (OPEs) in airborne particles were measured during a cruise campaign over the northern South China Sea (SCS) from September to October 2013. The concentration of the total OPEs ( $\sum$ OPEs) was $47.1-160.9 \mathrm{pg} \mathrm{m}^{-3}$, which are lower than previous measurements in marine atmosphere environments. Higher OPE concentrations were observed in terrestrially influenced samples, suggesting that OPE concentrations were significantly influenced by air mass transport. Chlorinated OPEs were the dominant OPEs, accounting for $65.8-83.7 \%$ of the $\sum$ OPEs. Tris-(2-chloroethyl) phosphate (TCEP) was the predominant OPE compound in the samples ( $45.0 \pm 12.1 \%$ ), followed by tris-(1-chloro-2-propyl) phosphates (TCPPs) $\left(28.8 \pm 8.9 \%\right.$ ). Dry particle-bound deposition fluxes ranged from 8.2 to $27.8 \mathrm{ng} \mathrm{m}^{-2} \mathrm{~d}^{-1}$ for the $\sum$ OPEs. Moreover, the dry deposition input of the $\sum$ OPEs was estimated to be 4.98 ton $\mathrm{y}^{-1}$ in 2013 in a vast area of northern SCS. About half of the input was found to relate to air masses originating from China. (c) 2015 Elsevier Ltd. All rights reserved.
* Corresponding authors: Tel.: +49 4152 872330; fax: +49 4152872332 (Z. Xie). Tel.: +861357097 4236 (Y. Zhang).

E-mail addresses: zhiyong.xie@hzg.de (Z.Xie), zhyy@scut.edu.cn (Y. Zhang).

\section{Introduction}

Organophosphate esters (OPEs) is a group of man-made chemicals widely applied as flame-retardants, plasticizer, antifoaming agents, and additives in hydraulic fluids, lacquers, and floor polishes 
(Reemtsma et al., 2008). OPEs can also be used as extractants in other processes such as hydrometallurgy and nuclear energy (Reemtsma et al., 2008). Measurements of OPE biodegradability and bioaccumulation in the environment date back to the 1970s and 1980s (Sheldon and Hites, 1978; Saeger et al., 1979). Fewer studies followed until concern re-emerged surrounding high environmental concentrations and the health risks from their use in indoor environments (Carlsson et al., 1997). OPEs are mostly used as flame-retardants, and the production has increased rapidly in the last decade due to the continuous phase-out of brominated flame-retardants such as polybrominated diphenyl ethers (PBDEs) (Stapleton et al., 2009). However, the environmental and health risks of OPEs are still not fully understood. Some halogenated OPEs have been found to exhibit various toxic effects (van der Veen and de Boer, 2012). For instance, tris-(2-chloroethyl) phosphate (TCEP) is toxic to aquatic organisms and is carcinogenic for animals. The adverse effects related to human health such as hemolytic and reproductive effects were also considered (van der Veen and de Boer, 2012). Discovery of these adverse effects caused the replacement of TCEP by tris-(1-chloro-2-propyl) phosphate (TCPPs) in Europe, but TCEP production is still not prohibited worldwide, and TCPP is also suggested to be potentially carcinogenic with low degradability in the environment (van der Veen and de Boer, 2012).

The existence of OPEs globally has been observed in the hydrosphere (Regnery et al., 2011; Bollmann et al., 2012), atmosphere (Regnery and Püttmann, 2009, 2010; Möller et al., 2012; Salamova et al., 2014b), and biosphere (Shah et al., 2006; Sundkvist et al., 2010). In the marine environment, OPEs were measured in seawater (Bollmann et al., 2012), biota (Sundkvist et al., 2010), and atmospheric particles (Möller et al., 2011, 2012; Castro-Jiménez et al., 2014; Salamova et al., 2014a). Riverine discharge as well as dry and wet deposition of particles is suggested to be the sources of OPEs in sea water (Regnery and Püttmann, 2009, 2010; Möller et al., 2011). Additionally, OPEs in marine aerosol particles can be influenced by long-range transport from continental regions (Aston et al., 1996). Currently the source influence, spatial distribution, and geochemical behaviors are not well investigated in marine environments due to limited studies as well as very variable concentrations (ranging from several $\mathrm{pg} \mathrm{m}^{-3}$ to several thousand $\mathrm{pg} \mathrm{m}^{-3}$ ) (Möller et al., 2011, 2012; Cheng et al., 2013; Castro-Jiménez et al., 2014; Harino et al., 2014).

In East Asia, the occurrence of OPEs in marine environments was only reported in a few studies (Kim et al., 2011; Möller et al., 2012; Cheng et al., 2013; Harino et al., 2014). The South China Sea (SCS) is a marginal sea surrounded by fast-developing regions leading to rapid increases in the production and consumption of industrial chemicals, including OPEs. Due to non-chemical bonding in materials, the release of OPEs from the surrounded regions into the SCS is highly likely during production and consumption. Here, we present a study on OPEs in marine atmospheric particles during a cruise campaign in the northern SCS from September to October 2013. It expands the current database of OPEs and helps to clarify the sources, behaviors, and environmental risks of OPEs in the marine environment.

\section{Experimental}

\subsection{Sampling information}

Air samples were taken during a 20-d cruise campaign in the north part of the SCS during the period of September to October 2013. The map is shown in Fig. 1 (prepared by the software of Ocean Data View) (Schlitzer, 2004).

Airborne particulate and gas samples were taken simultaneously. An integrated air sampler was placed in the upper deck of the vessel of Experiment III. A glass fiber filter (GFF, pore size $0.7 \mathrm{~m}$ ) and a self-made column containing XAD-2 resin were loaded to collect airborne particles and gaseous substances, respectively. The sampling volume of each air sample set was $\sim 300 \mathrm{~m}^{3}$. A total of 10 sets of air samples were collected during the campaign. The samples were stored at $-20^{\circ} \mathrm{C}$ after sampling and before analysis.

\subsection{Analysis}

The detailed description of sample pretreatment and analysis has been presented elsewhere (Möller et al., 2011; Bollmann et al., 2012). Briefly, the GFFs and the column were extracted separately. $\left[\mathrm{D}_{27}\right]$-TnBP and $\left[\mathrm{D}_{15}\right]$-TPP were spiked as internal standards (SI) before a Soxhlet extraction for $16 \mathrm{~h}$ using dichloromethane was performed. The extracts were roti-evaporated to $2 \mathrm{~mL}$ and purified on a $2.5 \mathrm{~g} 10 \%$ water deactivated silica gel column topped with $3 \mathrm{~g}$ of anhydrous granulated sodium sulfate. Analysis was then performed using an Agilent 6890 gas chromatograph coupled to an Agilent 5973 mass spectrometer (GC-MS) equipped with a programmed temperature vaporizer (PTV) injector. The GC was fitted with an HP-5MS column ( $30 \mathrm{~m} 0.25 \mathrm{~mm}$ i.d. $0.25 \mathrm{~mm}$ film thickness, J\&W Scientific) and was operated in electron impact mode. The information of the detected OPEs is shown in Table A1.

\subsection{Quality Assurance/Quality Control (QA/QC)}

The mean recovery rates of spiked experiments were from $107 \pm 4 \%$ (TCPP) to $139 \pm 12 \%$ (TEHP) for GFF filters $(n=3)$. The method detection limits (MDLs) were derived from the mean field blank concentrations plus three times the standard deviation $(3 \sigma)$ of the field blanks, which were within $0.3-6.8 \mathrm{pg} \mathrm{m}^{-3}$ for particle phase. The concentrations of OPEs are corrected with the recoveries of internal standards.

\subsection{Air mass back-trajectory analyses}

Air mass back-trajectories were calculated along the sampling route using NOAA's HYSPLIT model and were traced back $72 \mathrm{~h}$ at a height of $200 \mathrm{~m}$.

\section{Results and discussion}

\subsection{OPEs in the atmosphere}

We collected both particle and gas samples during the cruise to investigate the occurrence of OPEs in the atmosphere over the northern SCS. Nine OPEs were measured in airborne particulate samples including three chlorinated OPEs (TCEP, TCPPs, Tris(dichlorisopropyl)phosphate (TDCPP)), three alkyl phosphates (Tri-iso-butyl phosphate (TiBP), Tri- $n$-butyl phosphate (TnBP), Tris-(2-ethylhexyl) phosphate (TEHP)), and three aryl phosphates (Triphenyl phosphate (TPP), Triphenylphosphine oxide (TPPO) and Tricresyl phosphates (TCPs)). However, OPEs were not detected in the gas samples. Similar results have been reported in previous studies showing that OPE partitioning is limited to atmospheric particles (Möller et al., 2011, 2012; Salamova et al., 2014b). The concentrations of the detected OPEs in the particle samples and the box plot of the data are shown in Table A2 and Fig. A1, respectively.

Because TPP and TnBP are used in hydraulic fluids, we used the two species to check the possibility of contamination from ship exhaust (Marklund et al., 2005). The sampler was placed in the uppermost deck of the ship, which has the possibility to be influenced by the diffusion of ship emission. Therefore, we managed to collect samples mostly during ship cruising to avoid backwind contamination. The concentrations of TPP and TnBP were 


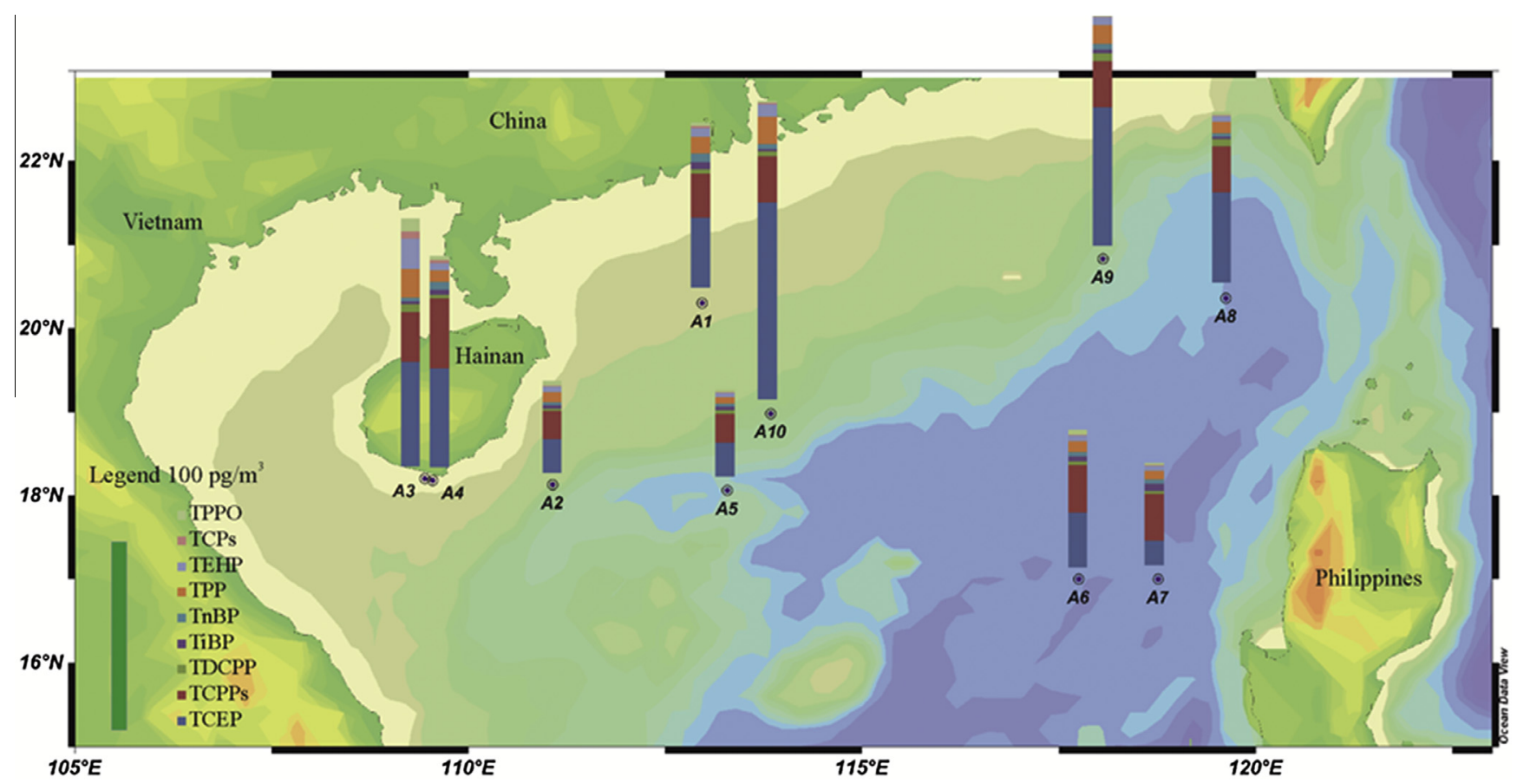

Fig. 1. Spatial distribution of OPEs in the atmosphere over the northern South China Sea.

$8.1 \pm 4.3 \mathrm{pg} \mathrm{m}^{-3}$ and $2.7 \pm 1.2 \mathrm{pg} \mathrm{m}^{-3}$, respectively. Compared to the results from other ship-based campaigns, the concentrations of TPP and TnBP were both lower in this study, showing the contamination from the ship exhaust is negligible (Möller et al., 2011, 2012; CastroJiménez et al., 2014).

The concentrations of the total OPEs ( $\sum$ OPEs) measured from the particle samples were in the range of $47.1-160.9 \mathrm{pg} \mathrm{m}^{-3}$ over the northern SCS. The profiles of the OPEs in the particle samples were investigated (see Fig. A2). Chlorinated OPEs were the most abundant OPEs measured in the airborne particles. The sum of the three chlorinated OPEs accounted for $76.8 \pm 6.5 \%$ of the $\sum$ OPEs, while alkyl- and aryl-OPEs comprised $11.4 \pm 3.6 \%$ and $11.9 \pm 3.8 \%$ of the $\sum$ OPEs, respectively. Among the chlorinated OPEs, TCEP and TCPPs were much more abundant than TDCPP in the particle samples. TCEP, the most dominant species in 9 of the 10 samples, was detected in the range of $18.6-106.7 \mathrm{pg} \mathrm{m}^{-3}$, accounting for $45.0 \pm 12.1 \%$ of the $\sum$ OPEs. TCPPs, the sum of three isomers, accounted for $28.8 \pm 8.9 \%$ of the $\sum$ OPEs. These chlorinated OPEs originate from the usage of flame retardants and have been found to exhibit various toxic effects (van der Veen and de Boer, 2012). TCEP is toxic to aquatic organisms and carcinogenic for animals and may cause other chronic adverse effects. The toxicity of TCPPs is lower than that of TCEP, but it is still considered potentially carcinogenic and exhibits low degradability (Ni et al., 2007). TPP and TEHP follow, making up $8.0 \pm 2.0 \%$ and $5.2 \pm 2.6 \%$ in the $\sum$ OPEs, respectively. The other OPE species are each found to comprise less than $5 \%$ in the $\sum$ OPEs.

The predominance of TCEP in the SCS differs from results reported for the Mediterranean, Black, and North Seas, where TCPPs were measured as the most dominant OPE (Möller et al., 2011; Castro-Jiménez et al., 2014). The difference could be the continue use of TCEP in the adjacent places around the SCS, while TCEP has been replaced by the lower toxic substitute TCPP in the European Union. The observed profiles of the OPEs in the particle samples are also very similar to those from a long-range cruise campaign conducted from Shanghai, China to the Arctic region, and in the southern hemisphere, from $30^{\circ} \mathrm{S}$ to the Antarctic region (Möller et al., 2012). The concentrations of the major OPE com- pounds, i.e., TCEP, TCPPs, TPP and TEHP, are much lower than those reported in urban and marine areas with high anthropogenic influences such as the North Sea (Möller et al., 2011), the Mediterranean Sea, the Black Sea (Castro-Jiménez et al., 2014), and coastal Japan (Harino et al., 2014). The levels are quite similar to the range of values measured in open and remote oceanic environments such as the Northern Pacific Ocean, Southern Ocean, and even in polar regions (Fig. 2) (Möller et al., 2012; Salamova et al., 2014a,b).

\subsection{Spatial variation of OPEs in atmospheric particles}

Higher concentrations of the $\sum$ OPEs were measured at a site near Hainan Island (samples A3 and A4) and during cruising along the coastal area of southern China (samples A9 and A10). When the ship was heading to and leaving from Hainan Island, much lower concentrations of the $\sum$ OPEs were measured $\left(47.7 \mathrm{pg} \mathrm{m}^{-3}\right.$ and $45.0 \mathrm{pg} \mathrm{m}^{-3}$ ). The variation of the OPE concentration can be influenced by many factors such as source region, air mass transport, and meteorological conditions (Cheng et al., 2013; Thouzeau et al., 2013; Liu et al., 2014). Because industrial production and usage of OPEs are so widespread, oceanic emissions are not expected to be a major contributor in the northern SCS. Nevertheless, this area is surrounded by many fast-developing regions, i.e., southern China, Taiwan, Vietnam, and the Philippines. Transport of anthropogenic air masses from the aforementioned regions may play an important role in the concentration variation (Möller et al., 2012; Cheng et al., 2013). Three-day back-trajectories along the sampling routes were calculated. Based on the majority of the air mass origins, the samples are partitioned into three groups: China origin, ocean origin, and mix origin (Fig. A3). The samples that collected mainly oceanic air masses (samples A2 and A5) had very low concentration for the $\sum$ OPEs $\left(48.5 \pm 1.9 \mathrm{pg} \mathrm{m}^{-3}\right)$ with especially low levels of TCEP $(18.3 \pm$ $\left.0.4 \mathrm{pg} \mathrm{m}^{-3}\right)$ and TCPPs $\left(15.5 \pm 0.7 \mathrm{pg} \mathrm{m}^{-3}\right)$. The samples considered to be from mixed source regions had moderate levels of $\sum$ OPEs $\left(83.6 \pm 24.8 \mathrm{pg} \mathrm{m}^{-3}\right)$ compared to the other two groups. The backtrajectories showed that the mixed air masses were traveling through both oceanic and terrestrial areas (including China, Taiwan, 

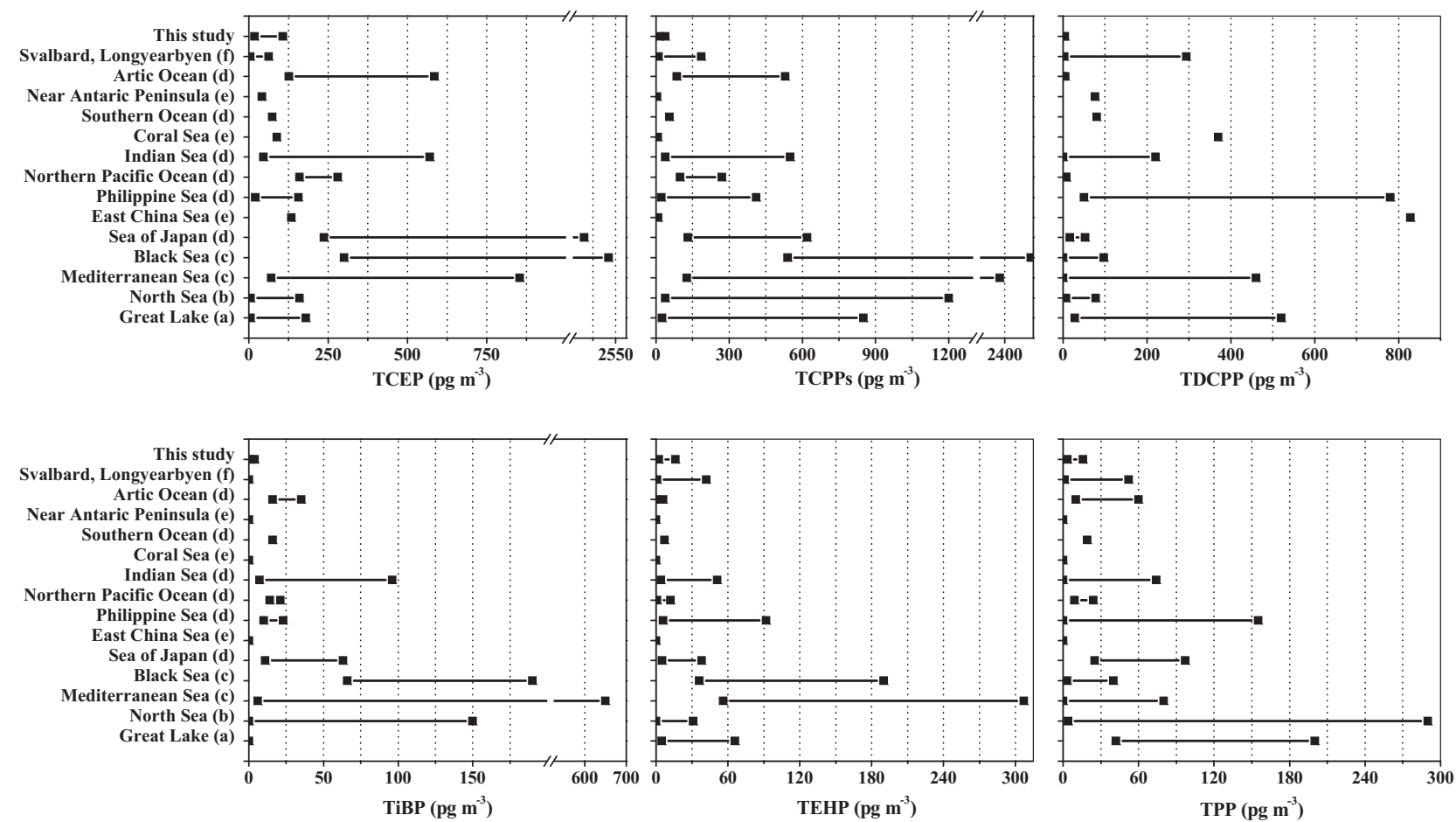

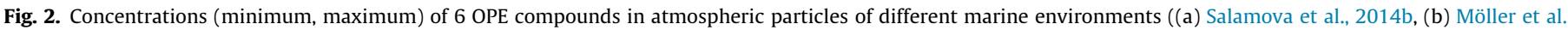
2011, (c) Castro-Jiménez et al., 2014, (d) Möller et al., 2012, (e) Cheng et al., 2013, and (f) Salamova et al., 2014a).

and the Indochinese Peninsula). The highest $\sum$ OPE concentrations were observed in the samples with air masses originating from China with an average of $128.1 \pm 28.1 \mathrm{pg} \mathrm{m}^{-3}$, which is as high as nearly three times that of the oceanic samples. It should be noted that the highest levels of TCEP were found in the samples with Chinese origin (samples A3, A8-A10), $71.8 \pm 25.8 \mathrm{pg} \mathrm{m}^{-3}$, and are more than three and two times higher than those of oceanic and mixed origin, respectively. Another chlorinated OPE, TDCPP, was also found at a higher level in the samples of Chinese origin $\left(3.9 \pm 0.8 \mathrm{pg} \mathrm{m}^{-3}\right)$ than in the mixed origin $\left(2.0 \pm 0.3 \mathrm{pg} \mathrm{m}^{-3}\right)$ and oceanic samples $\left(1.5 \pm 0.2 \mathrm{pg} \mathrm{m}^{-3}\right)$. On the other hand, the level of TCPPs in the samples of Chinese origin is higher than that of the oceanic samples, and similar to that of the mixed origin samples. The data indicate that China is an influential region for the source of OPEs and, specifically, for TCEP and TDCPP. Although the levels and characteristics of OPEs are not widely reported in China, some previous studies have outlined the large-scale production and usage of organophosphorus flame-retardants and their ubiquitous existence in the environment (Zeng et al., 2014). The growth rate of the production of flame retardant in China has continually increased in recent years. The gradual replacement of TCEP by TCPPs in Europe may be the reason that TCEP production in Asia has increased leading to the predominance of TCEP in the OPE profile in this study. However, without reliable emissions inventories of OPEs globally, especially in fast-developing areas such as China, the contribution, transport, and environmental behaviors of OPEs are still uncertain.

\subsection{Atmospheric dry deposition of OPEs to the northern South China} Sea

As shown in previous research as well as from the results in this study, OPEs are found to exist predominantly in the particle phase (Möller et al., 2011; Salamova et al., 2014b). The sink process of atmospheric particles, i.e., dry and wet depositions, is the prevailing way to link the occurrence of OPEs in water and in the particle phases in the oceanic area; wet scavenging is the most efficient way to remove particles from the atmosphere (Seinfeld and Spyros, 1998). Previous studies have reported the existence of OPEs in rain and snow (Regnery and Püttmann, 2009). Nevertheless, dry deposition remains a continuous mechanism of the input of particle pollutants into aquatic environments during periods without precipitation events. During this cruise campaign, all gas and particle samples were taken during non-precipitation periods. The dry deposition fluxes of OPEs $\left(F_{d}, \mathrm{ng} \mathrm{m}^{-2} \mathrm{~d}^{-1}\right)$ were calculated according to Eq. (1), shown as follows:

$F_{d}=V_{d} C_{p}$

where $V_{d}$ is the deposition velocity of atmospheric particles $(\mathrm{cm}$ $\left.\mathrm{s}^{-1}\right)$ and $C_{p}\left(\mathrm{ng} \mathrm{m}^{-3}\right)$ is the concentration of OPEs. There was no direct field measurement conducted to examine the deposition velocity of OPEs during the cruise. Referring to the estimations of OPEs in other sea areas, a value of $0.2 \mathrm{~cm} \mathrm{~s}^{-1}$ was adopted for our estimation (Möller et al., 2011; Castro-Jiménez et al., 2014). This value of $\mathrm{V}_{\mathrm{d}}$ has been used to estimate the dry deposition fluxes of OPEs in studies over the Mediterranean Sea, the Black Sea (Castro-Jiménez et al., 2014), and the North Sea (Möller et al., 2011), and is also within the range of a recent direct measurement of particle deposition during a dust event over the SCS $(0.2-0.6 \mathrm{~cm}$ $\mathrm{s}^{-1}$ ) (Hsu et al., 2013). The estimated dry deposition flux of the $\sum$ OPEs was $16.3 \pm 6.7 \mathrm{ng} \mathrm{m}^{-2} \mathrm{~d}^{-1}$ during the cruise and the individual dry deposition fluxes were from $0.2 \pm 0.2 \mathrm{ng} \mathrm{m}^{-2} \mathrm{~d}^{-1}$ for TCPs to $7.9 \pm 5.0 \mathrm{ng} \mathrm{m}^{-2} \mathrm{~d}^{-1}$ for TCEP (Fig. 4). The sum of three chlorinated OPEs had a dry deposition flux of $12.6 \pm 5.7 \mathrm{ng} \mathrm{m}^{-2} \mathrm{~d}^{-1}$, much higher than alkyl- and aryl-OPEs. The estimated dry deposition flux of the $\sum$ OPEs was lower than values reported in other oceanic areas (Möller et al., 2011; Cheng et al., 2013; Castro-Jiménez et al., 2014). As discussed above, the concentrations of OPEs in particles varies with air mass composition, which leads to the differences observed in the OPE depositions. Correspondingly, the highest dry deposition was estimated for samples of Chinese origin $\left(22.2 \pm 4.9 \mathrm{ng} \mathrm{m}^{-2} \mathrm{~d}^{-1}\right)$, followed by mixed origin samples $\left(14.5 \pm 4.3 \mathrm{ng} \mathrm{m}^{-2} \mathrm{~d}^{-1}\right)$ and oceanic samples $\left(8.4 \pm 0.3 \mathrm{ng} \mathrm{m}^{-2} \mathrm{~d}^{-1}\right)$. 


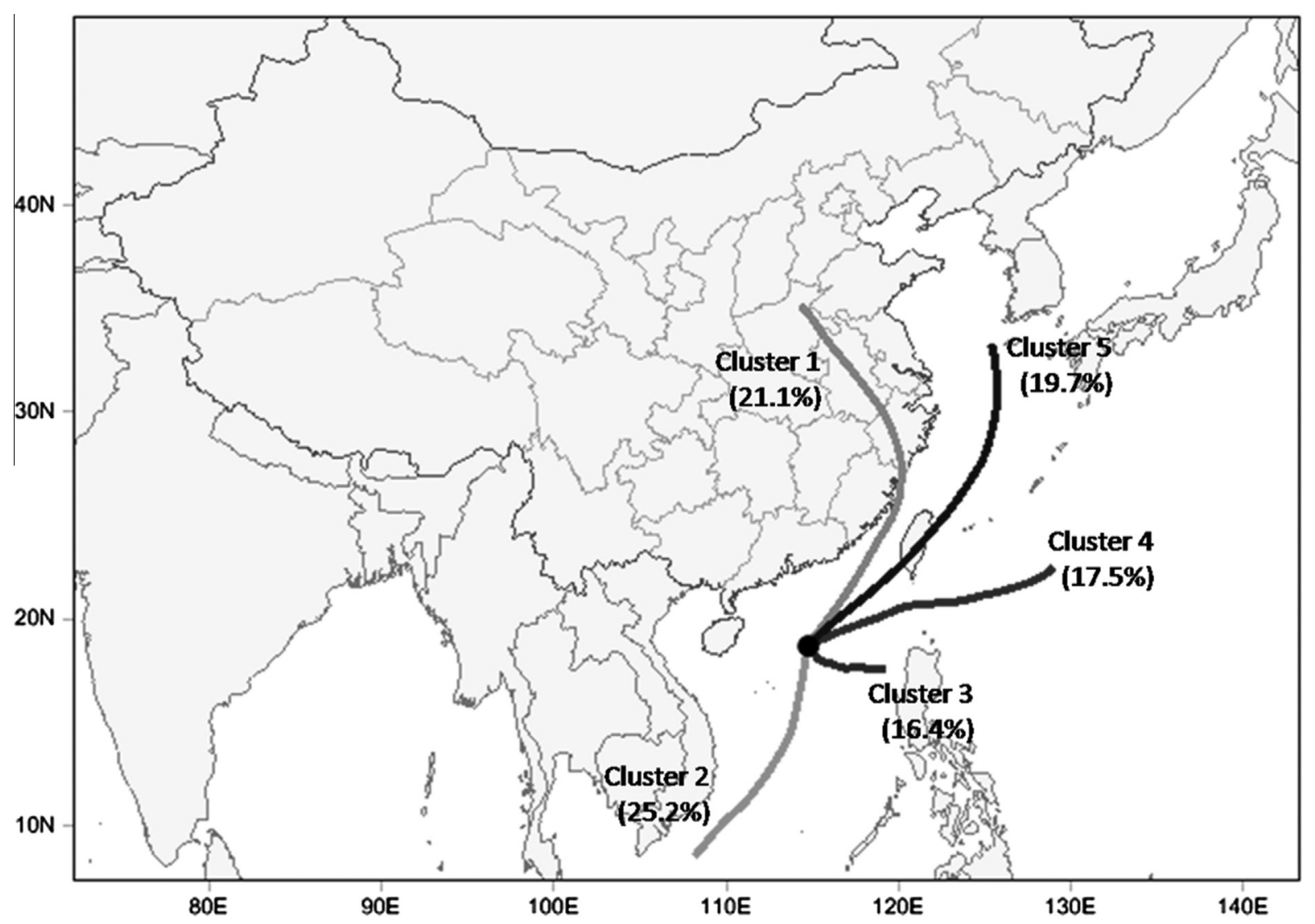

Fig. 3. Cluster analyses on the back-trajectories of the northern South China Sea during 2013.

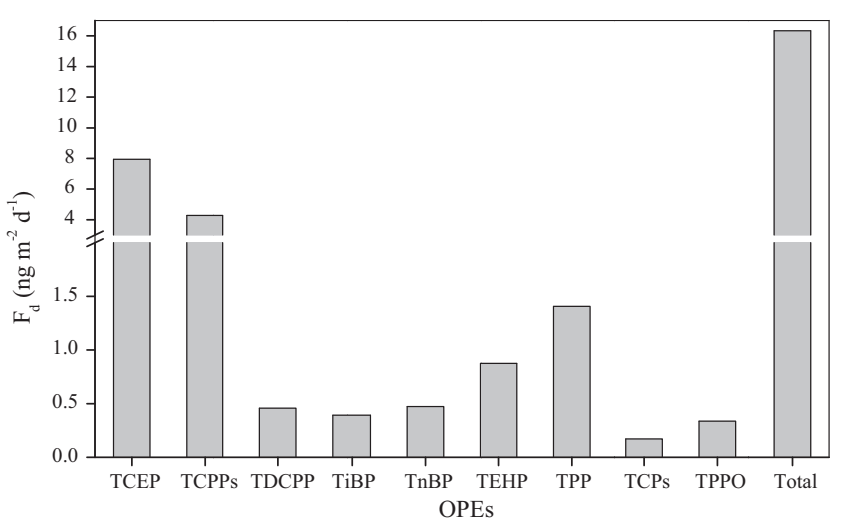

Fig. 4. The flux of dry deposition of OPEs over the northern South China Sea.

To achieve an estimation of the input of OPEs via dry deposition in the studied oceanic area, we first arbitrarily defined an area covering the ship cruising, i.e., latitudes between $14.77^{\circ} \mathrm{N}$ and $22.66^{\circ} \mathrm{N}$, and longitudes between $109.48^{\circ} \mathrm{E}$ and $120.00^{\circ} \mathrm{E}$, with an area of $\sim 958450 \mathrm{~km}^{2}$. Due to the observed influence of air mass transport on dry deposition fluxes, we performed cluster analyses on the 3-d back-trajectories in 2013 and investigated the air mass transport using TrajStat software (Wang et al., 2009). There are five clusters of back-trajectories obtained (Fig. 3). Cluster 1 represents the air masses transported from China accounting for $21.1 \%$. Cluster 4 is the influence of pure oceanic air masses (17.5\%). Cluster 2 originates from the southwestern area showing air masses influenced partly by the ocean and partly by mixed origins (oceanic together with Southeast Asian air masses). We assumed that half of them were oceanic (12.6\%) and half of them were mixed with oceanic and Southeast Asian air masses (12.6\%). The rest of the air masses represent the group of mixed origins, including Clusters 3 (16.4\%) and 5 (19.7\%). Therefore, we estimated the input of OPEs via dry deposition into the northern SCS taking into account dry deposition fluxes as well as the source origin influence. The estimated dry deposition input of the $\Sigma$ OPEs in 2013 was 4.98 ton $\mathrm{y}^{-1}$. The dry deposition inputs of chlorinated, alkyl-, and aryl-OPEs were 3.83 ton $\mathrm{y}^{-1}, 0.57$ ton $\mathrm{y}^{-1}$ and 0.58 ton $\mathrm{y}^{-1}$, respectively; furthermore, dry deposition introduced 2.24 ton $\mathrm{y}^{-1}$ of TCEP and 1.45 ton $\mathrm{y}^{-1}$ of TCPPs in the investigated sea area (Fig. A4). Calculations show that the air masses from China contributed about half of the dry deposition $(49.5 \pm 14.7 \%)$, much higher than for oceanic transport $(17.1 \pm 0.7 \%)$. According to previous research, riverine input is expected to be much larger than atmospheric dry deposition (Möller et al., 2011). However, without a survey on OPE levels in major waterways in the adjacent areas, especially in the southern China, we cannot compare the two OPE contributors. Due to the efficient removal of particles during precipitation, wet deposition of OPEs should not be neglected. Therefore, to better understand the cycle of OPEs in coastal and open ocean areas, it is important to further investigate the sources and release pathways of OPEs in anthropogenic areas and to investigate the transport and sink processes in varied conditions (e.g., topography, meteorology).

\section{Conclusions}

The occurrence of OPEs in atmospheric particulates was observed in a cruise campaign over the northern SCS. The concentration of $\sum$ OPEs was $47.1-160.9 \mathrm{pg} \mathrm{m}^{-3}$, which is relatively low compared to many previous observations of off-shore marine aerosol particles. Chlorinated OPEs were the dominant OPEs, accounting 
for $65.8-83.7 \%$ of the $\sum$ OPEs. TCEP was the predominant OPE compound found in the samples $(45.0 \pm 12.1 \%)$, followed by TCPPs $(28.8 \pm 8.9 \%)$. The observed profile of OPEs is different from those reported from many other polluted oceanic areas (especially in Europe), which is likely related to the increase of production and consumption of OPEs (e.g. TCEP) in East Asia. Air mass transport was found to play an important role in the variation of the measured OPE concentrations. Higher concentrations of OPEs were observed in the samples influenced by air mass transport from terrestrial regions, while oceanic air masses were suggested to be a minor source of influence. It indicates that the input of OPEs into the oceanic area via deposition processes is highly influenced by air mass transport. We estimated the dry particle-bound deposition fluxes of $8.2-27.8 \mathrm{ng} \mathrm{m}^{-2} \mathrm{~d}^{-1}$ for the $\sum$ OPEs, leading to the dry deposition input of 4.98 ton $\mathrm{y}^{-1}$ in 2013 in a vast area of northern SCS. The increasing production and consumption of organophosphorus flame-retardants and plasticizers in the surrounding areas will increase the input of OPEs into the SCS and cause potential long-term threat of adverse effects on marine environments. Due to the limited observation in the environments of the SCS, further research is necessary to investigate the occurrence, source, transport, and cycling of OPEs in the region.

\section{Acknowledgments}

The authors would like to thank the financial support of the National Natural Scientific Foundation of China (Grant Nos. 41105083, 41275130 and 41105084) and the Guangdong Natural Science Foundation (Grant Nos. S2012010009824 and S2011040005259).

\section{Appendix A. Supplementary material}

Supplementary data associated with this article can be found, in the online version, at http://dx.doi.org/10.1016/j.chemosphere. 2015.02.015.

\section{References}

Aston, L.S., Noda, J., Seiber, J.N., Reece, C.A., 1996. Organophosphate flame retardants in needles of pinus ponderosa in the Sierra Nevada foothills. Bull. Environ. Contam. Toxicol. 57, 859-866.

Bollmann, U.E., Möller, A., Xie, Z., Ebinghaus, R., Einax, J.W., 2012. Occurrence and fate of organophosphorus flame retardants and plasticizers in coastal and marine surface waters. Water Res. 46, 531-538.

Carlsson, H., Nilsson, U., Becker, G., Östman, C., 1997. Organophosphate ester flame retardants and plasticizers in the indoor environment: analytical methodology and occurrence. Environ. Sci. Technol. 31, 2931-2936.

Castro-Jiménez, J., Berrojalbiz, N., Pizarro, M., Dachs, J., 2014. Organophosphate ester (OPE) flame retardants and plasticizers in the open Mediterranean and Black Seas atmosphere. Environ. Sci. Technol. 48, 3203-3209.

Cheng, W., Xie, Z., Blais, J.M., Zhang, P., Li, M., Yang, C., Huang, W., Ding, R., Sun, L., 2013. Organophosphorus esters in the oceans and possible relation with ocean gyres. Environ. Pollut. 180, 159-164.

Harino, H., Yatsuzuka, E., Yamao, C., Ueno, M., Ohji, M., 2014. Current status of organophosphorus compounds contamination in Maizuru Bay, Japan. J. Mar. Biol. Assoc. UK 94, 43-49.

Hsu, S.-C., Tsai, F., Lin, F.-J., Chen, W.-N., Shiah, F.-K., Huang, J.-C., Chan, C.-Y., Chen, C.-C., Liu, T.-H., Chen, H.-Y., Tseng, C.-M., Hung, G.-W., Huang, C.-H., Lin, S.-H.,
Huang, 2013. A super Asian dust storm over the East and South China Seas: disproportionate dust deposition. J. Geophys. Res. Atmos. 118, 7169-7181.

Kim, J.W., Isobe, T., Chang, K.H., Amano, A., Maneja, R.H., Zamora, P.B., Siringan, F.P., Tanabe, S., 2011. Levels and distribution of organophosphorus flame retardants and plasticizers in fishes from Manila Bay, the Philippines. Environ. Pollut. 159, 3653-3659.

Liu, Y., Liggio, J., Harner, T., Jantunen, L., Shoeib, M., Li, S.M., 2014. Heterogeneous $\mathrm{OH}$ initiated oxidation: a possible explanation for the persistence of organophosphate flame retardants in air. Environ. Sci. Technol. 48, 1041-1048.

Marklund, A., Andersson, B., Haglund, P., 2005. Traffic as a source of organophosphorus flame retardants and plasticizers in snow. Environ. Sci. Technol. 39, 3555-3562.

Möller, A., Sturm, R., Xie, Z., Cai, M., He, J., Ebinghaus, R., 2012. Organophosphorus flame retardants and plasticizers in airborne particles over the Northern Pacific and Indian Ocean toward the Polar Regions: evidence for global occurrence. Environ. Sci. Technol. 46, 3127-3134.

Möller, A., Xie, Z., Caba, A., Sturm, R., Ebinghaus, R., 2011. Organophosphorus flame retardants and plasticizers in the atmosphere of the North Sea. Environ. Pollut 159, 3660-3665.

Ni, Y., Kumagai, K., Yanagisawa, Y., 2007. Measuring emissions of organophosphate flame retardants using a passive flux sampler. Atmos. Environ. 41, 3235-3240.

Reemtsma, T., Quintana, J.B., Rodil, R., García-López, M., Rodríguez, I., 2008. Organophosphorus flame retardants and plasticizers in water and air I. Occurrence and fate. TrAC. Trends Anal. Chem. 27, 727-737.

Regnery, J., Püttmann, W., 2009. Organophosphorus flame retardants and plasticizers in rain and snow from Middle Germany. Clean-Soil Air Water 37, 334-342.

Regnery, J., Püttmann, W., 2010. Seasonal fluctuations of organophosphate concentrations in precipitation and storm water runoff. Chemosphere 78, 958-964.

Regnery, J., Püttmann, W., Merz, C., Berthold, G., 2011. Occurrence and distribution of organophosphorus flame retardants and plasticizers in anthropogenically affected groundwater. J. Environ. Monit. 13, 347-354.

Saeger, V.W., Hicks, O., Kaley, R.G., Michael, P.R., Mieure, J.P., Tucker, E.S., 1979. Environmental fate of selected phosphate esters. Environ. Sci. Technol. 13, 840 844.

Salamova, A., Hermanson, M.H., Hites, R.A., 2014a. Organophosphate and halogenated flame retardants in atmospheric particles from a European Arctic site. Environ. Sci. Technol. 48, 6133-6140.

Salamova, A., Ma, Y., Venier, M., Hites, R.A., 2014b. High levels of organophosphate flame retardants in the Great Lakes atmosphere. Environ. Sci. Technol. Lett. 1, 814.

Schlitzer, R., 2004. Ocean Data View.

Seinfeld, J.H., Spyros, N.P., 1998. In: Atmospheric Chemistry and Physics: from Air Pollution to Climate Change. John Wiley \& Sons Inc.

Shah, M., Meija, J., Cabovska, B., Caruso, J.A., 2006. Determination of phosphoric acid triesters in human plasma using solid-phase microextraction and gas chromatography coupled to inductively coupled plasma mass spectrometry. J. Chromatogr. A 1103, 329-336.

Sheldon, L.S., Hites, R.A., 1978. Organic compounds in the Delaware River. Environ. Sci. Technol. 12, 1188-1194.

Stapleton, H.M., Klosterhaus, S., Eagle, S., Fuh, J., Meeker, J.D., Blum, A., Webster, T.F. 2009. Detection of organophosphate flame retardants in furniture foam and US house dust. Environ. Sci. Technol. 43, 7490-7495.

Sundkvist, A.M., Olofsson, U., Haglund, P., 2010. Organophosphorus flame retardants and plasticizers in marine and fresh water biota and in human milk. J. Environ. Monit. 12, 943-951.

Thouzeau, C., Henneuse, C., Sclavons, M., Devaux, J., Soulestin, J., Stoclet, G., 2013. Emission of volatile organic compounds during processing and use of organoclay-based nanocomposites. Polym. Degrad. Stab. 98, 557-565.

van der Veen, I., de Boer, J., 2012. Phosphorus flame retardants: properties, production, environmental occurrence, toxicity and analysis. Chemosphere 88, 1119-1153.

Wang, Y.Q., Zhang, X.Y., Draxler, R.R., 2009. TrajStat: GIS-based software that uses various trajectory statistical analysis methods to identify potential sources from long-term air pollution measurement data. Environ. Model. Softw. 24, 938-939.

Zeng, X., He, L., Cao, S., Ma, S., Yu, Z., Gui, H., Sheng, G., Fu, J., 2014. Occurrence and distribution of organophosphate flame retardants/plasticizers in wastewater treatment plant sludges from the Pearl River Delta, China. Environ. Toxicol Chem. 33, 1720-1725. 